\title{
Corrigendum: Probiotics, Anticipation Stress, and the Acute Immune Response to Night Shift
}

\author{
Nicholas P. West ${ }^{1 *}$, Lily Hughes ${ }^{1}$, Rebecca Ramsey ${ }^{1}$, Ping Zhang ${ }^{2}$, \\ Christopher J. Martoni ${ }^{3}$, Gregory J. Leyer ${ }^{3}$, Allan W. Cripps ${ }^{4}$ and Amanda J. Cox ${ }^{1}$ \\ ${ }^{1}$ School of Medical Science and Menzies Health Institute QLD, Griffith University, Gold Coast, QLD, Australia, ${ }^{2}$ Menzies \\ Health Institute QLD, Griffith University, Gold Coast, QLD, Australia, ${ }^{3}$ UAS Laboratories, Windsor, WI, United States, \\ ${ }^{4}$ School of Medicine and Menzies Health Institute QLD, Griffith University, Gold Coast, QLD, Australia
}

\section{OPEN ACCESS}

Edited and reviewed by: Margarida Castell,

University of Barcelona, Spain

*Correspondence:

Nicholas P. West

n.west@griffith.edu.au

Specialty section:

This article was submitted to Nutritional Immunology, a section of the journal

Frontiers in Immunology

Received: 22 May 2021 Accepted: 26 May 2021

Published: 21 June 2021

Citation:

West NP, Hughes L, Ramsey R, Zhang P, Martoni CJ, Leyer GJ, Cripps AW and Cox AJ (2021) Corrigendum: Probiotics, Anticipation Stress, and the Acute Immune Response to Night Shift.

Front. Immunol. 12:713237. doi: 10.3389/fimmu.2021.713237
Keywords: night shift, DDS-1, UABla-12, immunity, anticipatory stress

\section{A Corrigendum on}

Probiotics, Anticipation Stress, and the Acute Immune Response to Night Shift By West NP, Hughes L, Ramsey R, Zhang P, Martoni CJ, Leyer GJ, Cripps AW and Cox AJ (2021). Front. Immunol. 11:599547. doi: 10.3389/fimmu.2020.599547

In the original article, there was a mistake in Figure 2 as published. The asterisks to denote significance do not appear in the correct place. The corrected Figure $\mathbf{2}$ appears below.

The authors apologize for this error and state that this does not change the scientific conclusions of the article in any way. The original article has been updated.

In the published article, there was also an error in affiliation 3. Instead of "United Agricultural Services (UAS) Laboratories, Windsor, WI, United States", it should be "UAS Laboratories, Windsor, WI, United States".

The authors apologize for this error and state that this does not change the scientific conclusions of the article in any way. The original article has been updated.

Copyright (c) 2021 West, Hughes, Ramsey, Zhang, Martoni, Leyer, Cripps and Cox. This is an open-access article distributed under the terms of the Creative Commons Attribution License (CC BY). The use, distribution or reproduction in other forums is permitted, provided the original author(s) and the copyright owner(s) are credited and that the original publication in this journal is cited, in accordance with accepted academic practice. No use, distribution or reproduction is permitted which does not comply with these terms. 

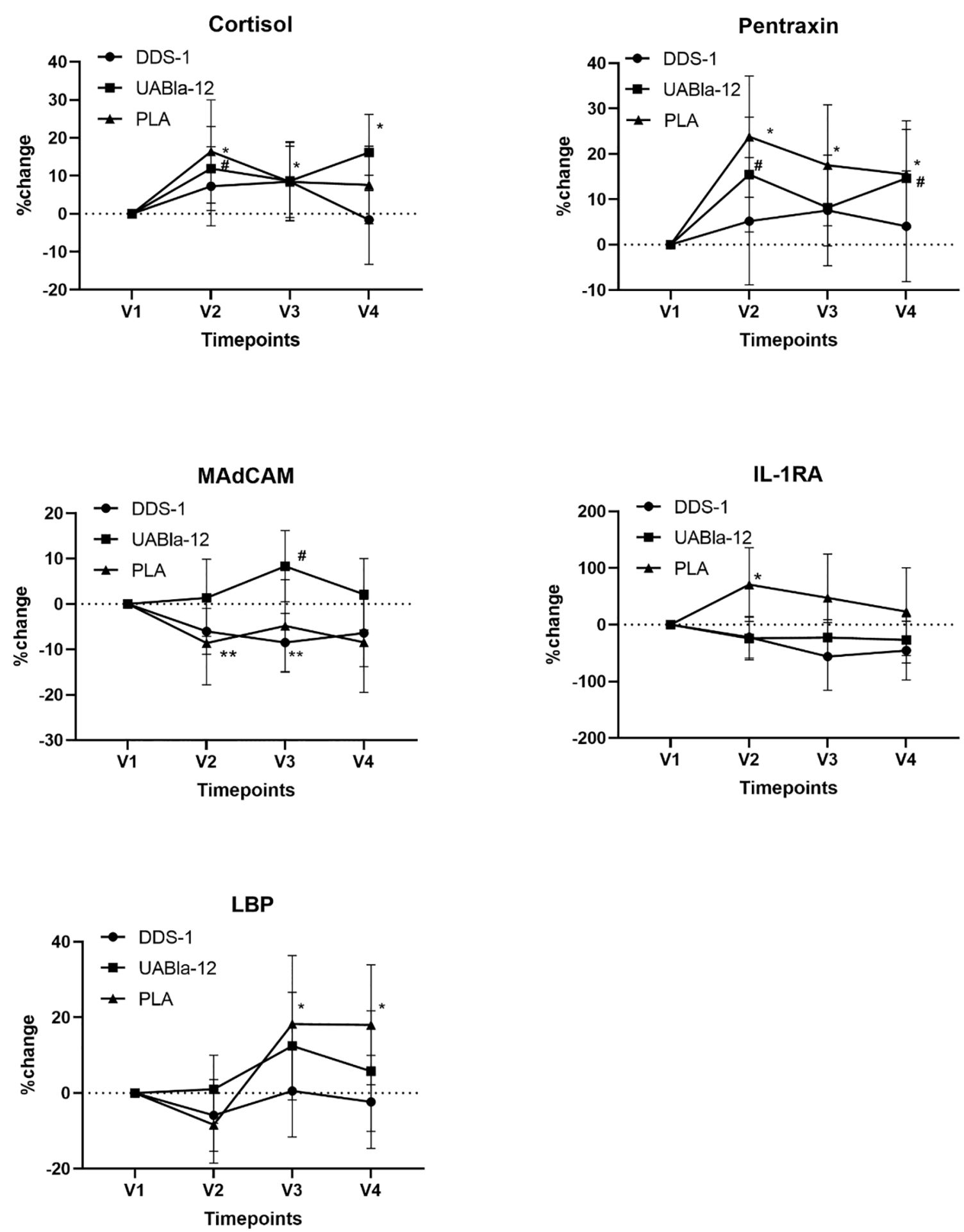

FIGURE 2 | Changes in the concentration of serum analytes over the course of the study. Significantly larger within group changes in the placebo group are evident in all analytes from V1 to V2. Data are \% change and 95\% Cl. The large changes in these analytes while adhering to typical night-day sleep-wake cycle were greater than the effect of nightshift on indices of stress, the acute phase response, serum cytokines and intestinal integrity markers. ${ }^{*}$ significant change from $\mathrm{V} 1$ in the placebo group, " significant change from V1 in UABla-12 group. ${ }^{\star *}$ significance chance from V1 in the DDS-1 group. 